\title{
Anatomy and Clinical Significance of Sacral Hiatus
}

\author{
Samia Khalid Khokhar, Aisha Qamar
}

\begin{abstract}
- - - - - - - - - - - - - - - - - - - - - - - - - ABSTRACT

The sacral hiatus is a gap on the dorsal surface of the sacrum formed by the non-fusion of the lamina of the fourth and fifth sacral vertebrae. A multitude of anatomical alternations of hiatus have been reported involving metric and non-metric parameters. These have been identified during radiological investigations, surgical procedures or discovered in anatomical and anthropological research studies. For successful outcomes in the clinical setting, it is vital that awareness of identified and newly discovered anatomical variations is achieved through review of literature. Objective of this article is to provide a systematic review of the reported anatomical variations of sacral hiatus with its clinical significance.
\end{abstract}

Key words: Anatomical variations, Clinical relevance, Sacral hiatus.

\section{INTRODUCTION:}

The sacral hiatus is a gap in the midline on the dorsal surface of the sacrum. It is formed by the non-union of the lamina of the fifth and less frequently fourth sacral vertebrae. On either side of this gap, the inferior articular processes of the fifth sacral vertebra extend downwards to form the sacral cornua ${ }^{1}$. The cornua are an important landmarkfor identification of the area of sacral hiatus. On gross examination the gap of the hiatus is usually shaped like a triangle, having an apex above and base below. The level of the apex may lie as high as the second sacral vertebraor as low as the fourth sacral vertebra. The base may be present at the coccyx, fifth or second sacral vertebra. An apex at the fourth sacral vertebra level is considered normal ${ }^{2}$.

Dry human sacral and radiological studies have revealed that the hiatus shapes range from triangular, U, inverted V, dumbbell, $\mathrm{M}$ to irregular ${ }^{3-5}$. Complete absence of hiatus has also been observed in $1.2 \%$ cases in African population ${ }^{6}$ and $2.22 \%$ in Indian population ${ }^{3}$. On the surface the hiatus is usually marked two inches above the tip of the coccyx beneath the natal cleftwith sacral cornua on each side. It is used to access the sacral nerves, coccygeal nerves and filum terminale present in the sacral canal for management of pain, administration of anesthetics, and endoscopy ${ }^{7-10}$.

Uses of sacral hiatus in thecaloscopy, trans-sacral endoscopy, myelography, minimally invasive spinal surgery and hernia repair have also been documented. It has been observed that for successful and complication free procedures, variations of sacral hiatus are to be taken into deliberation ${ }^{11-13}$. Symptoms of low back pain and urinary incontinence have also been

- Samia Khalid Khokhar

Senior Lecturer, Anatomy Department

Bahria University Medical and Dental College

I Email:dr.samia_khalid@hotmail.com

I

Aisha Qamar

Professor, Anatomy Department

I Bahria University Medical and Dental College

Received: 05-11-2019

I Accepted: 31-12-2019 ---------- associated with variations of sacral hiatus. Low back pain has been attributed to congenital absence of dorsal wall of sacrumwhich gives attachment to the extensor muscles of the spine. A decrease in the surface area for attachment of muscles of the back causes low back pain with minimal muscle spasm ${ }^{14-17}$.

\section{METHODOLOGY:}

A comprehensive search was undertaken using Google, Google Scholar, PubMed, Medline and Pakmedinet. Articles were selected from the years of 2009-2019 using keywords and phrases such as sacral hiatus anatomy, anatomical variations of sacral hiatus, clinical relevance, radiography, and morphometry. Articles irrelevant to the topic, outdated text and those written in foreign language were excluded. Total of 50 articles were selected and 45 were used for writing this review.

\section{Review of Literature:}

\section{Anatomy}

The sacrum has been considered as the keystone of the human body because it forms a link between the spine and hip bones. Its name has been derived from the Greek language meaning 'temple' or 'holy bone'. It was regarded as "sacred" by the ancient Egyptians and believed to be necessary for resurrection $^{19}$.

Anatomically, the sacrum is described as a "triangular" bone with a base, apex and ala (wing). The base is formed by the upper surface of the first sacral vertebra at the level of the sacroiliac joint. The base forms an angle of thirty degrees or more as it slopes downwards and forwards. It then curves down over the pelvic cavity. Considering the shape, the apex is formed as the base tapers off. The ala are formed by the fusion of the costal elements and transverse processes. They are present lateral to the body of the first sacral vertebra and are crossed from medial to lateral by the sympathetic trunk, lumbosacral trunk and the obturator nerve. The sacrum also has a concave, smooth pelvic surface, an auricular surface on lateral side for articulation with the ilium and a convex, rough, irregular dorsal surface. The pelvic surface has four 
ridges which are formed by the fusion of the bodies of the sacral vertebrae and represent the intervertebral discs. The sacral foramina are also present on the sides. These foramina transmit first to fourth sacral nerves. On the sides of the anterior sacral foramina is the lateral mass. It is related to the rami of anterior sacral nerves and gives attachment to the piriformis muscle. The dorsal surface is closed in the midline by the fusion of the laminae of the sacral vertebrae to the sacral crests. The fusion of the laminae, however, is not complete in the lower end leaving a gap through which the filum terminale passes to attach to the coccyx. A canal is formed in the midline of the sacrum that contains the meninges and posterior root ganglia of the sacral nerves. This is called the sacral canal and the gap inferior to it the sacral hiatus ${ }^{2}$.

The sacral hiatus is normally closed by fibrous tissue that forms the superficial sacrococcygeal ligament. On either side, it has the sacral cornua, which are an extension of inferior processes of the fifth sacral vertebra. These cornua are used to mark the area of the hiatus. The hiatus is also related to the area of attachment of intermediate layer of muscles of the back. These include the erector spinae muscle formed by the iliocostalis, longissimus and spinalis, gluteus maximus, and multifidus ${ }^{20}$.

\section{Morphometric Differences:}

Dry human sacral studies have revealed that variations in the shape, length, diameter and position of the sacral hiatus occur in different races and genders alike. Normally described as being triangular, the hiatus is stated to consist of an apex and a base. However, a variety of shapes have been documented. These include the inverted ' $U$ ', inverted ' $V$ ', $\mathrm{M}$, dumbbell, bifid and irregular ${ }^{4,20,21}$. Total absence of the sacral hiatus has also been reported in cases of congenital malformations of the vertebra such as spina bifida occulta. In Pakistan the overall incidence of congenital malformations of sacrum was found to be $34.5 \%$. The prevalence of incomplete and complete spina bifida was $5.5 \%$ and $4.5 \%$ respectively ${ }^{22}$.

Metric and non-metric analyses have been used in multiple morphometric studies involving the sacrum and sacral hiatus. Measurements of length, and antero-posterior and transverse diameters have been included in metric whereas levels of apex and base with reference to sacral vertebrae in nonmetric assessment tools. Measurements were made by digital calipers in millimeters. Landmarks for measurements of length, transverse and antero-posterior diameters were distance between the apex and the base of the hiatus, the sacral cornua and from anterior to posterior walls of the sacral canal ${ }^{5,23}$.

The length of the sacral hiatus has been linked to complications in procedures involving entry into the sacral canal $^{24,25}$. It has been found that the longer length of the sacral hiatus is directly related to increase in the incidence of dural puncture. Since the normal level of dural sac termination is at second sacral vertebra, a hiatus with long length has decrease in the distance between the apex of the hiatus and dural $\mathrm{sac}^{26,27}$. Measurements conducted in morphometric and radiographic studies have shown that length of sacral hiatus varies. Measured distances ranged from $28.7 \pm 7.1 \mathrm{~mm}^{13}, 20.6+8.8 \mathrm{~mm}^{17}, 18.88 \pm 7.58 \mathrm{~mm}^{21}, 32.9$ $\pm 9.9 \mathrm{~mm}^{28}$, and $11-30 \mathrm{~mm}$ (mean distance $\left.25.2 \mathrm{~mm}\right)^{29}$.

Anteroposterior diameter from the apex is significant when access to the sacral canal is required. A variety of observations related to geographic locations have been documented. In the Indian population $0.48 \mathrm{~cm}$ and $0.5 \mathrm{~cm}$ have been found ${ }^{17,21}$, Arabs $0.53 \mathrm{~cm}^{29}, 0.5 \mathrm{~cm}$ in White Americans and $0.6 \mathrm{~cm}$ in African Americans ${ }^{30}, 4.46 \mathrm{~cm}$ in Turkish population ${ }^{28}$ and $4.6+2 \mathrm{~mm}$ to $6.1+2.1 \mathrm{~mm}$ in Japanese population ${ }^{10}$. Furthermore, it was found that the diameter decreases with advancing age. A diameter of less than $3.7 \mathrm{~mm}$ was observed to cause difficulty in caudal epidural anesthesia ${ }^{10}$. The intercornual distance reported in various studies is also variable. An average of $19.5 \mathrm{~mm}$ in $\mathrm{Arab}^{13}, 17.47+3.23 \mathrm{~mm}^{17}$ in Turkish, $17 \mathrm{~mm}$ in Americans $\mathrm{s}^{30}$, 4.88mm in Indian ${ }^{31}$, and $10.2+0.35 \mathrm{~mm}$ was reported in Japanese population ${ }^{32}$.

Features which can be observed on gross examination of the bone either in radiographs or dry sacra are the nonmetric parameters. These include the shape, and level of the apex and the base with reference to the sacral vertebrae ${ }^{13}$.

Shape of the hiatus is one of the most important landmarks. Higher level of apex is not to be considered safe because of proximity to the termination of dura mater ${ }^{13}$. The most common shape observed has been the inverted ' $U$ ' as documented by Kumar et al $(41.5 \%)^{3}$. Bagheri $(33.33 \%)^{13}$, Aggarwal $(70.8 \%)^{21}$ and Nadeem $(56 \%)^{29}$.

An apex level at $\mathrm{S} 4$ has been a consistent finding in multiple studies ${ }^{3,13,21,32}$. Incidence of apex at S4 ranges from 60-68\%. Similar findings found in multiple studies indicating apex level at S4was observed in $70.11 \%$ of $\operatorname{Arab}^{13}, 68.42 \%$ as well as $76.23 \%$ Indian $^{17,21}$ and $65 \%$ of Japanese ${ }^{32}$ populations. Apex at other levels was also found including $1 \%$ at $\mathrm{S1}^{32}$, $62 \%$ at $\mathrm{S}^{29}$, and $11.49 \%$ at $\mathrm{S}^{13}$. The level of apex is used to decide the length of the needle to be used in interventional procedures. In majority of studies, it has been found at the level of S4 with incidence of 60-68\% ${ }^{13,17,21,32}$. These findings are in agreement with another study which observed apex at level of S4 in $65-68 \%$ of the sacral vertebra ${ }^{10}$. Base of the sacral hiatus has been frequently observed to lie at $\mathrm{S} 5^{17,21,29}$.

\section{Clinical Significance:}

\section{Caudal epidural anesthesia/analgesia}

It involves injection of anesthetic through the sacral hiatus to access the epidural space. It can be used for management of chronic pain, surgical anesthesia and analgesia in children and adults. Thorough knowledge of sacral hiatus anatomy 
helps to improve the success rate of this technique ${ }^{10}$. It can also be used in orthopedic practice and obstetrics ${ }^{11,32}$. Identification of apex and antero-posterior diameter of sacral hiatus is crucial for successful procedure. Safe option for access is through the base of the hiatus ${ }^{21,28}$. Anatomic abnormalities may cause failure of caudal epidural block in $3-11 \%$ patients $^{32}$. Sacral hiatus approach was also used in anorectal surgeries for regional anesthesia. It was found that success rates of caudal epidural anesthesia increases with experience of the surgeon and that it has significant results in pain reduction ${ }^{33,34}$.

\section{Thecaloscopy}

It is a minimally invasive procedure used to access the subarachnoid space. A flexible endoscope is used to access the thecal space. Sacral hiatus can be used for trans-sacral endoscopy. Dimensions of sacral hiatus width (transverse diameter), lumbosacral angle and level of termination of dural sac are necessary for complication free procedure ${ }^{35,36}$.

Myelography, Treatment of Urinary Incontinence and Urological Calculi

Sacral hiatus can also be used as a potential route for stimulation of sacral nerves in the treatment of urinary incontinence in post-operative patients especially after radical prostatectomy. A study observed significant difference in response rates of sacral nerve stimulation totally by sacral hiatus when compared to alternate route via sacral foramina. Route involving sacral hiatus had $60 \%$ positive response rate whereas alternate route had $20 \%$ response rate ${ }^{37}$.

\section{Mechanical low back pain}

Low back pain may be associated with a decrease in surface area for the attachment of the extensor muscles of the back on the dorsal wall of the sacrum ${ }^{16}$. In a study it was found that the dorsal wall of sacra was deficient in $40 \%$ male as compared to $27.2 \%$ females. According to the study, $7.5 \%$ of cases had no sacral hiatus ${ }^{17}$. High percentage of low back pain was associated with variable deficient wall in the referred articles ${ }^{16,17}$.

\section{Congenital Anomalies}

Anomalies related to sacrum include spina bifida. In Pakistan overall incidence was $34.5 \%$. Prevalence of incomplete spina bifida was $5.5 \%$ and complete defect was $4.5 \%$. Symptoms of backache, urinary and neurological symptoms were prevalent in such cases ${ }^{22}$.

\section{Methods of Studying the Hiatus}

\section{Radiological}

$\mathrm{X}$-ray of lumbosacral spine, pelvis or sacrum has been used for studying the sacrum and hiatus. More advanced techniques such as CT scan and MRI have been used for detailed imaging via three dimensional views ${ }^{38}$. Ultrasound has also been used for determination of optimal angle of needle insertion for caudal epidural anesthesia and comparison between male and female patients with low back pain ${ }^{39-41}$. Anthropometric

Majority of the studies used dry human sacra for morphometric, and comparison studies. These studies assessed the differences observed in male and female sacra with their clinical significance, anatomical variations related to locations, racial variations and related congenital anomalies $^{42-45}$.

\section{CONCLUSION:}

The sacral hiatus is a gateway to access the sacral and coccygeal nerves. It has significant potential as an alternate route in surgical, palliative and interventional procedures. Variations related to the length of the hiatus have potential clinical implications and require further investigations.

\section{REFERENCES:}

1. Standring S. Gray's Anatomy. $41^{\text {st }}$ ed. London: Elsevier Churchill Livingstone; 2016. p. 726-9.

2. Sinnatamby CS. Last's Anatomy Regional and Applied. $12^{\text {th }}$ ed. London: Churchill Livingstone; 2011: p 665-70.

3. Kujur B, Gaikwad MR. A Study of Variations in Sacral Hiatus and Its Clinical Significance. IJIMS 2017; 4(2): 204-12.

4. Singh A, Gupta R, Singh A. Morphological and Morphometrical Study of Sacral Hiatus of Human Sacrum. Natl J Integr Res Med2018; 9(4):65-73.

5. Mustafa MS, Mahmoud OM, El Raouf HHA, Atef HM. Morphometric Study Of Sacral Hiatus In Adult Human Egyptian Sacra: Their Significance In Caudal Epidural Anesthesia. Saudi J Anaesth 2012; 6(4):330-57.

6. Osuwoke EA, Oladipo GS, Allison TA, Orlu E. A Study of Sacral Hiatus in Dry Human Sacra in Southern Nigeria. JHMN 2014; 3:51-5.

7. Lakshmi TA, Azrajabeen. Surgically Relevant Morphometry of Sacral Hiatus. Anatomica Karnataka, 2013;7(1): 52-6.

8. Bhatacharya S, Majumdar S, Chakraborty P, Mazumdar S, Mazumdar A. A Morphometric Study of Sacral Hiatus for Caudal Epidural Block among the Population of West Bengal. Indian Journal of Basic and Applied Medical Research 2013; 7(2):660-67.

9. Woon J, Stringer MD. The Anatomy of the Sacrococcygeal Cornual Region and Its Clinical Relevance. Anat Sci Int 2013; 89(4):207-14.

10. Kao SC, Lin CS. Caudal Epidural Block: An Updated Review of Anatomy and Techniques. Biomed Research International 2017: $1-5$.

11. Ahmm K, Ara S, Ashrafuzzaman M, Khatun K, Islam MS Morphometry of Sacral Hiatus and its Clinical Relevance in Caudal Epidural Block. J. Dhaka Med Coll 2014; 23(1):316.

12. Vasuki AK, Sundaram KK, Nirmaladevi M, Jamuna M, Hezibkah DJ, Fenn TKA. Anatomical Study of the Sacrum and its Clinical Significance. Int J Anat Res 2016; 2(3):1237.

13. Bagheri H, Govsa F. Anatomy of the Sacral Hiatus and Its Clinical Relevance in Caudal Epidural Block. Surg Radiol Anat 2017; 39:943-51. 
14. Prasad N, Prasad M. A Study Of Hiatal Level In Sacrum: Is This The Cause of Back Problems In Indians. Journal of Evidence Based Medicine Healthcare 2016; 3(47):2318-21.

15. Secer M, Muradov JW, Dalgi A. Evaluation of Congenital Lumbosacral Malformations and Neurological Findings in Patients with Low Back Pain. Turkish Neurosurgery 2009; 19(2):145-8.

16. Elumalai G, Thangamani M, Sanyal S, Kanagarajan P. Deficient Sacral Hiatus Cause Mechanical Low Back Pain: A Radiological Study. International Journal of Anatomy and Research 2016; 4(1):1758-64.

17. Kumar V, Nayak SR, Potu BK, Pulakunta T. Sacral Hiatus in Relation to Low Back Pain in South Indian Population. Bratisl Lek Listy 2009; 110(7):436-41.

18. Bhadra RC, Saha D. Relation of Low Back Pain with Level of Sacral Hiatus in West Bengal Population-An Osteoradiological Study. Indian Journal of Basic and Applied Medical Research 2017; 6(3):140-7.

19. Nastoulis E, Karakasi MV, Pavlidis P, Thomaidis V, Fiska A. Anatomy and Clinical Significance Of Sacral Variations: A Systematic Review. Folia Morphologica 2019: 1-45.

20. Moore KL, Dalley AF, Agur AMR. Clinically Oriented Anatomy. $18^{\text {th }}$ ed. Philadelphia: Lippincott Williams and Wilkins; 2018. p. 270-4.

21. Aggarwal A, Kaur H, Batra YK, Aggarwal AK, Rajeev S, Sahni D. Anatomic Consideration of Caudal Epidural Space: A Cadaver Study. Clin Anat 2009; 22:730-7.

22. Ali S, Azeemi AA, Shoukat S. The Prevalence of Spina Bifida Occulta in Pakistani Population: A Study of Dry Human Sacra. Anesthesia Pain and Intensive Care 2014; 18(2):157-61.

23. Kilicaslan A, Keskin F, Babaoglu O, Gok F, Erdi MF, Karya B, et al. Morphometric Analysis of the Sacral Canal and Hiatus Using Multidetector Computed Tomography for Interventional Procedures. Turk Neurosurgery 2015; 25(4):56673

24. Park G, Kwon DR, Cho HK. Anatomic Differences in the Sacral Hiatus During Caudal Epidural Injection Using Ultrasound Guidance. J Ultrasound Medicine 2015; 34:21438.

25. Nasr AY. Clinical Relevance of Conus Medullaris and Dural Sac Termination Level with Special Reference to Sacral Hiatus Apex: Anatomical and MRI Radiologic Study. Anat Sci Int 2017; 92:456-67.

26. Bagheri H, Govsa F. Anatomy of the Sacral Hiatus and Its Clinical Relevance in Caudal Epidural Block. Surgical Radiological Anatomy 2017; 39:943-51.

27. Pal DR, Rahman A, Fatema K. Morphometric Study of Sacral Hiatus: A Basis for Successful Caudal Epidural Block. Bangladesh Journal of Anatomy 2012; 10(1):5-10.

28. Senoglu N, Senoglu M, Oksuz H, et al. Landmarks of the Sacral Hiatus for Caudal Epidural Block: An Anatomical Study. Br J Anaesth 2005; 95:662-95.

29. Nadeem G. Importance of Knowing the Level of Sacral Hiatus for Caudal Epidural Anesthesia. J Morphol Sci 2014; 31(1):913.
30. Trotter M. Variations Of The Sacral Canal: Their Significance In The Administration Of Caudal Analgesia.ÊAnesth Analg.Ê1947;26: 192-202.

31. Mayuri J, Vijay G, Vasudha N, Anita G, Asha P. Anatomical Study of Sacral Hiatus in Dry Isolated Sacra. J Res Med Dent Sci 2014; 2(2): 43-6.

32. Sekuguchi M, Yabuki S, Satoh K, Kikuchi S. An Anatomic Study of the Sacral Hiatus: A Basis for Successful Caudal Epidural Block. Clin J Pain 2004; 20(1):51-4.

33. Jaffer Al-sa'adi MH. Assessment of Surgeon Performed Caudal Block for Anorectal Surgery. Asian J Surg 2018;42(1):240-3.

34. Canakci E, Yagan O, Tas N, Mutlu T, Cirakoglu A, Benli E. Comparison of Preventive Analgesia Techniques In Circumcision Cases: Dorsal Penile Nerve Block, Caudal Block or Subcutaneous Morphine? J Pak Med Assoc 2017; 67(2): 159-65.

35. Mourgela S, Sakellaropoulos, Anagnostopolou S, Warnke JP. The Dimensions of Sacral Spinal Canal in Thecaloscopy: A Morphometric MRI Study. Neuroanat 2009; 8:1-3.

36. Pradhan A, Yadav S. Assessing the Dimension of Sacral Spinal Canal for Thecaloscopy Using MRI. Int J Pharm Bio Sci 2016; 7(1): 588-592.

37. ElSawy NA, Mahran HG and Alkushi AG. Impact of Therapeutic Electrical Stimulation of Sacral Surface Considering Individual Anatomical Sacral Variations on Early Recovery Urinary Incontinence after Radical Prostatectomy. FMAR 2017; 5:1-13

38. Yilmaz S, Tokpinar A, Acer N, Dogan S. Morphometric Investigation of the Sacral Bone in MR Images. J US China Med Sci 2019; 16:179-85.

39. Domingo T, Bong DA, Mayoral V, Ortega R, Perez MM, Sabate A. Ultrasound-Guided Pain Interventions In The Pelvis And Sacral Spine. Tech Reg Anesth Pain Manag 2013; 17:107130.

40. Kim DH, Park HJ, Lee SC. Ultrasonographic Evaluation of Anatomic Variations of Sacral Hiatus: Implications for Caudal Epidural Injections. Spine 2016;41(13):759-63.

41. Nakahashi M, Uei H, Hashino M, Omori K, Igarashi H, Tokuhashi Y. Anatomical Evaluation of Sacral Hiatus Using Ultrasound Imaging: Factors That Inhibit Needle Insertion During Caudal Epidural Block Procedures. Pain Prac 2013; 1(7):11-18

42. Shinde VK, Shirbadgi SA. Study of Variations in Levels of Sacral Hiatus. Int J Anat Res 2016; 4(1):1882-85.

43. Chauhan R, Nagar M. Anatomical Profile and Morphometric Evaluation of Human Sacral Hiatus in Northern Indians. J Surg Acad 2015; 5(2):8-12.

44. Duncan MA, Sherriff M, O'Keeffe D, Dangerfield PH. A Radiographic Assessment of the Distances from Sacral Hiatus To The Lower Lumbar Spinous Processes. Eur J Anat 2009; 13(1): 19-22.

45. Ali S, Qureshi I, Ali A. Anatomical Variations of Sacral Hiatus in Dry Human Sacra. JIMC 2015; 10(1):121-3. 